Research Article

\title{
A Descriptive Study to Assess the Correlation between Knowledge and Practice of ASHA Workers regarding Services provided under National Health Mission working in Selected Primary Health Centres of Tangmarg, Baramulla with a View to Develop Information Booklet
}

\author{
Noorul Amin', Dilshada Wani ${ }^{2}$, Bilqis Yasmin ${ }^{3}$ \\ ${ }^{1}$ MSc Nursing (Community Health Nursing) Scholar, ${ }^{2}$ Professor Cum Principal, ${ }^{3}$ Senior Tutor, MMINSR, SKIMS, Soura, Srinagar, \\ Jammu and Kashmir, India. \\ DOI: https://doi.org/10.24321/2348.2141.202006
}

I $\quad \mathbf{N} \quad \mathbf{F} \quad \mathbf{O}$

Corresponding Author:

Noorul Amin, MMINSR, SKIMS, Soura, Srinagar, Jammu and Kashmir, India.

E-mail Id:

noorul.amin@skims.ac.in

Orcid Id:

https://orcid.org/0000-0002-9631-376X

How to cite this article:

Amin N, Wani D, Yasmin B. A Descriptive Study to Assess the Correlation between Knowledge and Practice of ASHA Workers regarding Services provided under National Health Mission working in Selected Primary Health Centres of Tangmarg, Baramulla with a View to Develop Information Booklet. Trends Nurs Adm Edu 2020; 9(2): 21-39.

Date of Submission: 2020-12-02

Date of Acceptance: 2020-12-25

\section{$\begin{array}{llllllll}\text { A } & \text { B } & \mathbf{S} & \mathbf{T} & \mathbf{R} & \mathbf{A} & \mathbf{C} & \mathbf{T}\end{array}$}

Introduction: The study was conducted to assess the knowledge and practice levels of ASHAworkers regarding services provided under the National Health Mission (NHM). These levels were further correlated to know whether they are related or not. It aimed at providing deficient information to ASHA workers, and at motivating them to sustain their efforts for adequate practice.

Methods: A non-experimental descriptive (correlative) research design was used. 60 ASHA workers were selected from the accessible population using convenient sampling technique. The prepared tools (self-structured knowledge questionnaire and practice checklist) and Information Booklet were validated by a panel of experts, and were pre-tested for clarity and feasibility. A pilot study was conducted on $10 \%$ of ASHA workers. The main study was conducted from 9th September 2020 to 20th September 2020. The data collected was analysed by using descriptive and inferential statistics.

Result: The study revealed that majority of the ASHA workers had average knowledge and adequate practice regarding services provided under NHM. There was a significant association of their knowledge scores regarding services provided under NHM with their educational status. No significant association was found between their practice scores and their demographic variables. A moderately strong positive correlation was found between their knowledge and practice regarding services provided under NHM.

Conclusion: The findings of the study concluded that ASHA workers working in Primary Health Centres of Tangmarg, Baramulla had average knowledge and adequate practice regarding services provided under NHM. However, some components need to be focused on.

Keywords: ASHA Workers, Services Under NHM, Knowledge, Practice

Trends in Nursing Administration \& Education (ISSN: 2348-2141) 


\section{Introduction}

In India, about 70 per cent of people live in rural areas. As there is a lack of decentralisation of health services, so the people living in these areas do not have proper hospital facilities and access to health care. A high proportion of the population, especially in rural areas, continues to suffer and die from preventable diseases like malnutrition, complications related to pregnancy, and childbirth. Recognising the importance of health in the process of economic and social development and to improve the quality of life of citizens, the Government of India launched "National Rural Health Mission" (NRHM) on 5th April 2005 for a period of 7 years (2005-2012). The mission seeks to improve the rural health care delivery system. It is operational in the whole country with a special focus on 18 states (UT of Jammu and Kashmir included). By making necessary changes in the basic health care delivery system, the mission adopts a synergic approach by relating health to the determinants of good health, nutrition, sanitation, hygiene, and safe drinking water. It also included the Indian system of medicine in the mainstream of health care. ${ }^{1}$

The main aim of National Rural Health Mission (NRHM) is to provide accessible, affordable, accountable, effective, and reliable primary health care, and to bridge the gap in rural health care by creating a cadre of community health workers popularly known as Accredited Social Health Activist (ASHA). ${ }^{2}$

The Government of India (Gol) found a positive impact of NRHM, and hence decided to convert it into National Health Mission (NHM) in May 2013 to provide health care to the urban poor under National Urban Health Mission (NUHM) in the course of 12th five-year plan. National Urban Health Mission (NUHM) envisages meeting the health care needs of the urban population with a focus on the urban poor by making available to them essential primary health care services and reducing their pocket expenses for availing different services, facilities, and treatment. Now NUHM and NRHM are functioning as sub-missions of $\mathrm{NHM}^{3}$

The main initiatives under NHM include strengthening of the health system in rural and urban areas, ASHA, Rogi Kalyan Samiti, Hospital Management Society, the untied grants to Sub-Centres, The Village Health Nutrition and Sanitation Committee (VHN\&SC), Janani Suraksha Yojana (JSY), Janani Shishu Suraksha Karyakram (JSSK), Newborn Care, National Ambulance Services, Free Drugs/ diagnostic Service Initiative, Maternal \& Child Health services, Reproductive Child Health, and prevention and control of communicable diseases. The NHM envisages the achievement of universal access to equitable, affordable, and quality healthcare services that are accountable and responsive to people's needs. ${ }^{3}$

The country deals with multiple health crises, rising cost of health care, and mounting expectation of the people, and the National Health Mission (NHM) is a major instrument of financing that provides support to the states to strengthen public health systems and healthcare delivery. This financing to the states is based on the State's Programme Implementation Plan (PIP) and is fully sponsored by the Central Government of India. Nowadays we can see that NHM is running in all states and union territories, where health status is low. ${ }^{4}$

The number of ASHA workers working in J\&K as per the report published by NHM in "update on ASHA programme" is 11843 . The same report has proposed a requirement for 12000 more ASHA workers for J\&K. There are about 1026 ASHA workers working in the Baramulla district of J\&K. ${ }^{4}$

Out of the above-mentioned number of ASHA workers, 3000 appeared in the National Institute of Open Schooling (NIOS) examination and got certified for the job. Out of this,399 appeared from the district Baramulla. ${ }^{5}$

ASHA programme of J\&K was awarded at the national level because of its excellent performance and unique institutionalisation. ${ }^{6}$

\section{Objectives}

- To assess the knowledge score of ASHA workers regarding services provided under NHM.

- To assess the practice score of ASHA workers regarding services provided under NHM.

- To associate the knowledge score of ASHA workers regarding services provided under NHM with selected demographic variables (age, educational status, marital status, experience, and in-service training received under NHM).

- To associate the practice score of ASHA workers regarding services provided under NHM with the selected demographic variables (age, educational status, marital status, experience, and in-service training received under NHM).

- To find out the correlation between knowledge and practice score of ASHA workers regarding services provided under NHM.

\section{Methods}

\section{Research Approach}

While going through the problem statement and objectives of the research study, a quantitative research approach was used because it was found to be the most appropriate for achieving the objectives of the study titled "A descriptive study to assess the correlation between knowledge and practice of ASHA workers regarding services provided under National Health Mission working in selected Primary Health Centres of Tangmarg, Baramulla with a view to develop Information Booklet." 


\section{Research Design}

In this study, a non-experimental research design was used for the overall research process. A subtype of this design, i.e. descriptive (correlative) research design, was used for the present study.

\section{Variables}

The following variables were included in the research study.

\section{Demographic Variables}

These refer to the personal characteristics of the study subjects. In this study, these refer to the personal characteristics of ASHA workers. Here, the demographic variables included are age, educational status, marital status, experience, and in-service training received under NHM.

\section{Research Variables}

These refer to the variables that are actually under study. In this study, research variable refers to the knowledge and practice of ASHA workers regarding services provided under the National Health Mission.

\section{Setting of the Study}

The present study was conducted in seven selected Primary Health Centres of Tangmarg Baramulla (Gulmarg, Babareshi, Gogaldara, Hariwatnoo, Khaipora, Warpora, and Nambilnara) from 9th September 2020 to 20th September 2020. The selection of setting was done on the basis of nature and purpose of the problem statement, feasibility of conducting the research study, availability of the sample, and familiarity of the researcher with the research setting.

\section{Study Population}

A population is the entire aggregation of cases in which a researcher is interested. Population is a set of people or entities to which the results of a research study are to be generalised. In the present study, the population consists of all ASHA workers working in selected Primary Health Centres of Tangmarg, Baramulla.

\section{Sampling Technique and Sample}

Non-probability convenient sampling technique was used for the selection of study subjects to be included in the study. The sample size for the present research study comprised 60 ASHA workers working in selected Primary Health Centres of Tangmarg, Baramulla (Gulmarg, Babareshi, Gogaldara, Hariwatnoo, Khaipora, Warpora, and Nambilnara).

\section{Criteria for Selection of Sample}

The researcher specifies the characteristics of the population by setting inclusion and exclusion criteria in the study. Inclusion criteria are the characteristics that each sample must possess to be included in the study. Exclusion criteria are the characteristics that a participant may have, which makes him or her unfit for the study as they confound the results of the final study.

Following criteria were set for the selection of study subjects in the research study:

\section{Inclusion Criteria}

ASHA workers who fulfilled the following criteria were selected for the study:

- Working in the selected Primary Health Centres of Tangmarg, Baramulla.

- Available at the time of data collection.

\section{Statistical Tools Used to Analyse the Data}

The data analysis was planned based on the objectives and hypothesis of the study. It was planned to organise, tabulate, analyse, and interpret data using both descriptive and inferential statistics. The following plan of analysis was developed with the opinion of experts:

1. The collected data was coded and transferred to a master sheet for statistical analysis.

2. Frequency and percentage distribution were computed to describe the sample characteristics.

3. The knowledge scores of the study subjects regarding services provided under NHM were analysed in terms of mean, median, and standard deviation.

4. The practice scores of the study subjects regarding services provided under NHM were analysed in terms of mean, median, and standard deviation.

5. Chi-square test was used to associate the knowledge and practice score of ASHA workers regarding services provided under NHM with selected demographic variables (age, educational status, marital status, experience, and in-service training received under NHM).

6. Karl Pearson's product-moment correlation method was used to determine the correlation between knowledge and practice of ASHA workers regarding services provided under NHM.

7. The findings were interpreted and presented with the help of tables and graphs. The level of significance was set as the conventional level of $p<0.05$ to test the hypothesis.

\section{Ethical Consideration}

Ethical clearance is necessary when research is conducted on human beings. Prior permission was obtained from the concerned authorities (Principal of MMINSR, SKIMS, and BMO Tangmarg) to conduct the research study. Prior permission from the BMO Tangmarg was obtained through a requisition letter forwarded from the office of Principal, MMINSR to conduct the study. A synopsis was presented 
and submitted to the Institutional Ethics Committee of SKIMS, Soura Srinagar for ethical clearance and permission. The purpose of conducting the study on ASHA workers at Primary Health centres of Tangmarg was explained to BMO Tangmarg and Block ASHA coordinator. The purpose and objectives of the study were also explained to the ASHA workers working in the Primary Health Centres of Tangmarg, Baramulla. The permission from study subjects was obtained through informed consent, taken individually from each of the ASHA workers, prior to their inclusion as a study subject in this research. The privacy, confidentiality, and anonymity of study subjects were being guarded.

\section{Result}

The data collected were analysed using both descriptive (frequency, mean, median, SD, range) and inferential statistics (Chi-square test and Karl Pearson's ProductMoment Method of Correlation). The data was compiled, stored, and coded in MS excel spreadsheet, and was analysed with the help of SPSS software (Version 20.0) (SPSS Inc., Chicago, Illinois, USA). All the inferences were checked at $p<0.05$ level of significance. The findings have been tabulated according to the plan for data analysis.

Table I.Mean \pm SD, Median, Mode, and Range of Knowledge Score of Study Subjects

$(N=60)$

\begin{tabular}{|c|c|c|c|c|}
\hline $\begin{array}{c}\text { Knowledge } \\
\text { Score }\end{array}$ & Mean \pm SD & Median & Mode & Range \\
\hline & $38.16 \pm 6.01$ & 37.79 & 37 & 29 \\
\hline
\end{tabular}

Table 1 , shows that the mean \pm SD of knowledge score of study subjects was $38.16 \pm 6.01$, with a median of 37.79 , mode of 37, and range of 29 .

Table 2.Distribution of Study Subjects according to their Frequency and Percentage of Knowledge Level regarding Services provided under NHM

$(N=60)$

\begin{tabular}{|c|c|c|}
\hline $\begin{array}{c}\text { Knowledge Level } \\
\text { (Score) }\end{array}$ & $\begin{array}{c}\text { Frequency } \\
\text { (f) }\end{array}$ & $\begin{array}{c}\text { Percentage } \\
\text { (\%) }\end{array}$ \\
\hline Poor $(<30)$ & 03 & 05 \\
\hline Average $(31-40)$ & 37 & 61.67 \\
\hline Excellent $(>40)$ & 20 & 33.33 \\
\hline Total & 60 & 100 \\
\hline
\end{tabular}

Table 2, shows that maximum (61.67\%) study subjects were having average knowledge, while $33.33 \%$ of the study subjects were having excellent knowledge, and a minority (5\%) of the study subjects had poor knowledge regarding services provided under NHM.

Table 3, shows that the mean \pm SD knowledge of study subjects was $7.31 \pm 1.35$ regarding the concept of NHM, 9.91 \pm 1.22 for maternal health services, $2.9 \pm 0.93$ for JSY services provided under NHM, $3.63 \pm 0.85$ for JSSK services provided under NHM, $8.93 \pm 1.92$ for child health and immunisation, and $6.86 \pm 1.62$ for other miscellaneous services.

Table 3.Area wise Mean \pm SD, Median, Mode, and Range of Knowledge of Study Subjects regarding Services provided under NHM

\begin{tabular}{|c|c|c|c|c|}
\hline $\begin{array}{l}\text { Knowledge Areas } \\
\text { regarding Services } \\
\text { provided under } \\
\text { NHM }\end{array}$ & $\begin{array}{c}\text { Mean } \\
\pm \text { SD }\end{array}$ & Median & Mode & Range \\
\hline $\begin{array}{c}\text { Part A } \\
\text { Concept of NHM }\end{array}$ & \begin{tabular}{|c|}
$7.31 \pm$ \\
1.35 \\
\end{tabular} & 7 & 7 & 9 \\
\hline $\begin{array}{c}\text { Part B } \\
\text { Maternal Health } \\
\text { Services Provided } \\
\text { under NHM } \\
\end{array}$ & $\begin{array}{c}9.91 \pm \\
1.22\end{array}$ & 9 & 9 & 5 \\
\hline $\begin{array}{c}\text { Part C } \\
\text { JSY Services } \\
\text { Provided under } \\
\text { NHM }\end{array}$ & $\begin{array}{l}2.9 \pm \\
0.93\end{array}$ & 3 & 3 & 4 \\
\hline $\begin{array}{c}\text { Part D } \\
\text { JSSK Services } \\
\text { Provided under } \\
\text { NHM } \\
\end{array}$ & $\begin{array}{c}3.63 \pm \\
0.85\end{array}$ & 4 & 4 & 4 \\
\hline $\begin{array}{c}\text { Part E } \\
\text { Child Health and } \\
\text { Immun. Services } \\
\text { Provided under } \\
\text { NHM }\end{array}$ & $\begin{array}{c}8.93 \pm \\
1.92\end{array}$ & 9 & 10 & 8 \\
\hline $\begin{array}{c}\text { Part F } \\
\text { Other Misc. Services } \\
\text { Provided under } \\
\text { NHM }\end{array}$ & $\begin{array}{c}6.86 \pm \\
1.62\end{array}$ & 7 & 7 & 6 \\
\hline
\end{tabular}

Thus it can be inferred from the findings that the study subjects were having the highest knowledge regarding maternal health services, followed by child health and immunisation, concept of NHM, JSSK services provided under NHM, JSY services provided under NHM, and other miscellaneous services provided under NHM.

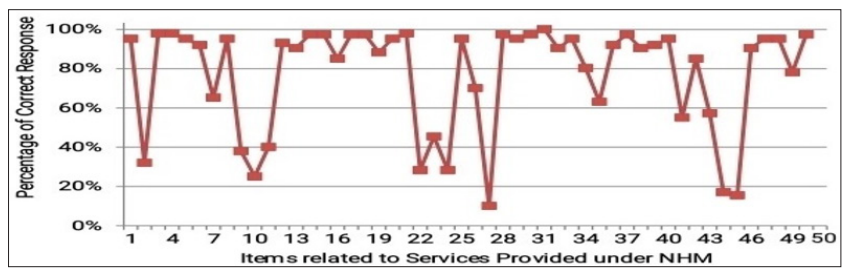

Figure I.Item Analysis of Percentage Distribution of Correct Responses on Self-structured Knowledge Questionnaire 
Figure 1 depicts that $100 \%$ of study subjects were able to answer item number 31 while only $15 \%$ were able to answer item number 45 in the self-structured knowledge questionnaire.

Thus it can be inferred that the study subjects were well acquainted with BCG immunisation of child at birth and were less aware that ASHA kits were being provided to them for various procedures (Refer Appendix).

Table 4. Mean \pm SD, Median, Mode, and Range of Practice Score of Study Subjects

\begin{tabular}{|c|c|c|c|c|}
\hline $\begin{array}{c}\text { Practice } \\
\text { Scores }\end{array}$ & Mean \pm SD & Median & Mode & Range \\
\hline & $12.58 \pm 1.6$ & 13.48 & 13.81 & 11 \\
\hline
\end{tabular}

Table 4 , depicts that mean \pm SD of practice score of study subjects was $12.58 \pm 1.6$, with a median of 13.48 , mode of 13.81, and range of 11 .

Table 5.Distribution of Study Subjects according to their Frequency and Percentage of Practice Level regarding Services provided under NHM

\begin{tabular}{|c|c|c|}
\hline \multicolumn{2}{|c}{$(\mathrm{N}=60)$} \\
\hline Practice Level & Frequency (f) & Percentage (\%) \\
\hline $\begin{array}{c}\text { Poor }(\leq 5) \\
\text { Adequate }(6-10)\end{array}$ & 01 & 1.67 \\
\hline Adequate $(>10)$ & 56 & 05 \\
\hline Total & 60 & 93.33 \\
\hline
\end{tabular}

Table 5, shows that majority, i.e. 93.33\%, of the study subjects were having adequate practice, while $5 \%$ were having moderately adequate practice, and only $1.67 \%$ had poor practice regarding services provided under NHM.

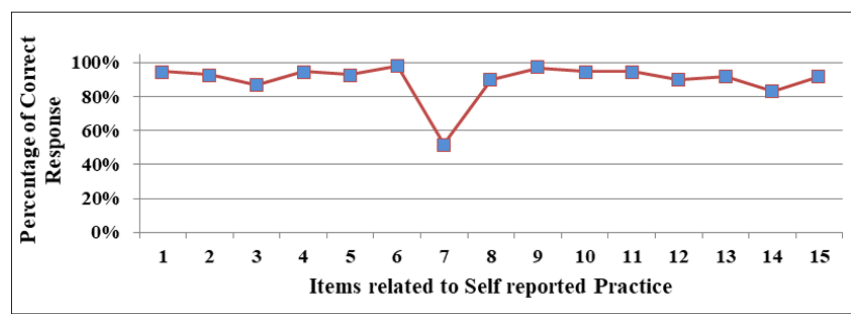

Figure 2.Item Analysis of Percentage Distribution of Correct Responses on Practice Checklist

Figure 2, reveals that maximum (95\%-98\%) study subjects had given correct response to item number 1,4,6,9,10,11, while minimum correct response was given to item number 7 (by $52 \%$ of study subjects).

Thus it can be inferred that the study subjects participate more in maternal health (Refer Appendix). It is also interpreted that they have not yet taken up the role of DOTS provider fully.

$\mathrm{Ho}_{1}$ : There is no significant association between the knowledge score of ASHA workers regarding services provided under NHM with selected demographic variables (age, educational status, marital status, experience, and in-service training received under NHM) at 0.05 level of significance.

Table 6, reveals that statistically, a significant association was found between the knowledge scores of study subjects and their educational status $(p=0.014)$ whereas no association was found with age, marital status, experience, and inservice training received under NHM.

Hence the researcher failed to reject the null hypothesis H01 for demographic variables [age $(p=0.28)$, marital status $(p=0.231)$, years of experience $(p=0.537)$, and inservice training received under $\operatorname{NHM}(p=0.526)]$ except for educational status ( $p=0.014$ ) with which association was highly significant at $<0.05$ level of significance.

Table 6.Association of Knowledge Scores of Study Subjects regarding Services provided under NHM with the Selected Demographic Variables

\begin{tabular}{|c|c|c|c|c|c|c|c|c|c|}
\hline \multicolumn{2}{|c|}{$\begin{array}{c}\text { Demographic } \\
\text { Variables }\end{array}$} & $\begin{array}{c}\text { Poor } \\
\text { Knowledge }\end{array}$ & $\begin{array}{c}\text { Average } \\
\text { Knowledge }\end{array}$ & $\begin{array}{c}\text { Excellent } \\
\text { Knowledge }\end{array}$ & $\begin{array}{l}x 2 \\
\text { Test }\end{array}$ & $\begin{array}{l}\text { Table } \\
\text { value }\end{array}$ & df & $\begin{array}{c}\mathbf{p} \\
\text { value }\end{array}$ & Result \\
\hline \multirow{4}{*}{$\begin{array}{c}\text { Age } \\
\text { (in years) }\end{array}$} & $21-30$ & 1 & 6 & 0 & \multirow{4}{*}{7.47} & \multirow{4}{*}{12.59} & \multirow{4}{*}{6} & \multirow{4}{*}{0.28} & \multirow{4}{*}{ NS\# } \\
\hline & $31-40$ & 1 & 23 & 15 & & & & & \\
\hline & $41-50$ & 2 & 7 & 3 & & & & & \\
\hline & $51-60$ & 0 & 1 & 1 & & & & & \\
\hline \multirow{3}{*}{ Educational Status } & 8th & 2 & 30 & 7 & \multirow{3}{*}{12.45} & \multirow{3}{*}{9.49} & \multirow{3}{*}{4} & \multirow{3}{*}{0.014} & \multirow{3}{*}{$\mathrm{S}^{*}$} \\
\hline & 10th & 2 & 6 & 9 & & & & & \\
\hline & 12 th & 0 & 1 & 3 & & & & & \\
\hline \multirow[t]{2}{*}{ Marital Status } & Married & 0 & 0 & 1 & \multirow{2}{*}{5.59} & \multirow{2}{*}{9.49} & \multirow{2}{*}{4} & \multirow{2}{*}{0.231} & \multirow{2}{*}{ NS\# } \\
\hline & Unmarried & 3 & 32 & 18 & & & & & \\
\hline
\end{tabular}




\begin{tabular}{|c|c|c|c|c|c|c|c|c|c|}
\hline & Other & 1 & 5 & 0 & & & & & \\
\hline \multirow{3}{*}{ Experience (in years) } & $1-5$ & 0 & 3 & 1 & \multirow{3}{*}{1.72} & \multirow{3}{*}{9.49} & \multirow{3}{*}{4} & \multirow{3}{*}{0.537} & \multirow{3}{*}{ NS\# } \\
\hline & $6-10$ & 1 & 13 & 6 & & & & & \\
\hline & $11-15$ & 3 & 21 & 12 & & & & & \\
\hline \multirow{2}{*}{$\begin{array}{l}\text { In-service Training } \\
\text { received under NHM }\end{array}$} & Yes & 4 & 35 & 19 & \multirow{2}{*}{1.28} & \multirow{2}{*}{5.99} & \multirow{2}{*}{2} & \multirow{2}{*}{0.526} & \multirow{2}{*}{ NS\# } \\
\hline & No & 0 & 2 & 0 & & & & & \\
\hline
\end{tabular}

*Significant $\leq 0.05$

\#Non-Significant $>0.05$

Table 7.Association of Practice Scores of Study Subjects regarding Services provided under NHM with their selected Demographic Variables

$(N=60)$

\begin{tabular}{|c|c|c|c|c|c|c|c|c|c|}
\hline \multicolumn{2}{|c|}{$\begin{array}{c}\text { Demographic } \\
\text { Variables }\end{array}$} & $\begin{array}{c}\text { Poor } \\
\text { Practice }\end{array}$ & $\begin{array}{c}\text { Moderately } \\
\text { Adequate } \\
\text { Practice }\end{array}$ & $\begin{array}{l}\text { Adequate } \\
\text { Practice }\end{array}$ & $\begin{array}{l}\text { u2 } \\
\text { Test }\end{array}$ & $\begin{array}{l}\text { Table } \\
\text { value }\end{array}$ & df & $\begin{array}{c}\mathbf{p} \\
\text { value }\end{array}$ & Result \\
\hline \multirow{4}{*}{$\begin{array}{c}\text { Age } \\
\text { (in years) }\end{array}$} & $21-30$ & 1 & 0 & 6 & \multirow{4}{*}{8.4} & \multirow{4}{*}{12.59} & \multirow{4}{*}{6} & \multirow{4}{*}{0.20} & \multirow{4}{*}{ NS\# } \\
\hline & $31-40$ & 0 & 2 & 37 & & & & & \\
\hline & $41-50$ & 0 & 1 & 11 & & & & & \\
\hline & $51-60$ & 0 & 0 & 2 & & & & & \\
\hline \multirow{3}{*}{ Educational Status } & 8th & 0 & 2 & 37 & \multirow{3}{*}{2.8} & \multirow{3}{*}{9.49} & \multirow{3}{*}{4} & \multirow{3}{*}{0.60} & \multirow{3}{*}{ NS\# } \\
\hline & 10th & 1 & 1 & 15 & & & & & \\
\hline & 12th & 0 & 0 & 4 & & & & & \\
\hline \multirow{3}{*}{ Marital Status } & Married & 0 & 0 & 1 & \multirow{3}{*}{9.5} & \multirow{3}{*}{9.49} & \multirow{3}{*}{4} & \multirow{3}{*}{0.10} & \multirow{3}{*}{ NS\# } \\
\hline & Unmarried & 0 & 3 & 50 & & & & & \\
\hline & Other & 1 & 0 & 5 & & & & & \\
\hline \multirow{3}{*}{ Experience (in years) } & $1-5$ & 0 & 0 & 4 & \multirow{3}{*}{4.0} & \multirow{3}{*}{9.49} & \multirow{3}{*}{4} & \multirow{3}{*}{0.40} & \multirow{3}{*}{ NS\# } \\
\hline & $6-10$ & 1 & 0 & 19 & & & & & \\
\hline & $11-15$ & 0 & 3 & 33 & & & & & \\
\hline \multirow{2}{*}{$\begin{array}{l}\text { In-service Training } \\
\text { received under NHM }\end{array}$} & Yes & 1 & 3 & 54 & \multirow{2}{*}{0.1} & \multirow{2}{*}{5.99} & \multirow{2}{*}{2} & \multirow{2}{*}{0.90} & \multirow{2}{*}{ NS\# } \\
\hline & No & 0 & 0 & 2 & & & & & \\
\hline
\end{tabular}

*Significant $\leq 0.05$

\#Not Significant $>0.05$

Thus it can be interpreted from the association table that the educational status of study subjects plays an important role in the acquisition of knowledge regarding services provided under NHM whereas the other factors don't play such a role here in the study.

$\mathrm{Ho}_{2}$ : There is no significant association between the practice score of ASHA workers regarding services provided under NHM with selected demographic variables (age, educational status, marital status, experience, and in-service training received under NHM), at 0.05 level of significance.

Table 7, reveals that statistically, no significant association was found between the practice scores of study subjects with their age, educational status, marital status, experience, and in-service training received under NHM.
Hence the researcher failed to reject the null hypothesis $\mathrm{H} 02$ for demographic variables [age $(p=0.20)$, educational status $(p=0.60)$, marital status $(p=0.10)$, experience in years $(p=0.40)$, and in-service training received under $\operatorname{NHM}(p=0.90)]$ at $p<0.05$ level of significance.

Thus it can be interpreted that the selected demographic variables don't interfere with the practice level of study subjects. This can be due to the fact that all of the activities performed by the study subjects are incentive-based which motivates them to perform adequately to gain the monetary benefit.

$\mathrm{Ho}_{3}$ : There is no significant positive correlation between knowledge and practice of ASHA workers regarding services provided under NHM, at 0.05 level of significance. 
Table 8.Correlation between Knowledge and Practice Score of Study Subjects regarding Services provided under National Health Mission

$(\mathrm{N}=60)$

\begin{tabular}{|c|c|c|c|c|c|c|c|}
\hline Item & Mean \pm SD & Median & Pearson's Coefficient $(\boldsymbol{r})$ & $\mathbf{r}$ Tabulated & df & p value & Result \\
\hline Knowledge & $38.16 \pm 6.01$ & 37.79 & 0.69 & 0.25 & 58 & 0.001 & S* \\
\cline { 1 - 3 } Practice & $12.58 \pm 1.6$ & 13.48 & & & & & \\
\hline
\end{tabular}

*Statistically Significant at $\mathrm{p}<0.01$

Table 8, shows that there is a perfect positive correlation between knowledge and practice of ASHA workers regarding services provided under NHM, by using Pearson's coefficient method. The coefficient of correlation between knowledge and practice is found to be $r=0.69$ with $p$ value $=0.001$.

Hence the researcher rejected the null hypothesis $\mathrm{HO}$ which states that there is no significant positive correlation between knowledge and practice of ASHA workers regarding services provided under NHM as the coefficient of correlation between knowledge and practice is found to be $r=0.69$ with $p$ value $=0.001$, which is highly significant at 0.05 level of significance.

Thus it can be interpreted that the knowledge level of study subjects has an impact on their practice level.

\section{Discussion}

The major findings of the present study, based on the objectives are discussed in relation to the previous studies conducted by other investigators as follows.

The findings of the present study revealed that the majority of study subjects, i.e. $61.67 \%$, had obtained scores between 31 and 40, and 33.33\% had scored between 41 and 50, followed by $5 \%$ who scored between 0 and 30 . The study concluded that the mean \pm SD knowledge of the study subjects was $38.16 \pm 6.01$, median was 37.79 , mode was 37 , and range was 29 . This implies that the researcher had found that $61.67 \%$ of study subjects had average knowledge, $33.33 \%$ ) of study subjects had excellent knowledge, and $5 \%$ of the study subjects had poor knowledge regarding services provided under NHM.

The findings of the present study are supported by a study conducted by Mohapatra A, Mohapatra SC (2013) ${ }^{7}$ on, "Intra-organizational human resource auditing of ASHAs in Harahua block of Varanasi with ( $N=209)$ ". The study revealed that the mean knowledge score was found to be 2.11 on a 3-point Likert scale, with 39\% ASHAs ranking average, $36 \%$ ranking good, and $25 \%$ ranking poor.

The above findings are also supported by a study conducted by Gupta A (2017), ${ }^{8}$ on "A Study on Knowledge and Practice of ASHA under NHM Programme of Allahabad District conducted on 405 ASHA workers" in Uttar Pradesh, India. The study revealed that majority of ASHA workers (52.10\%) had a medium level of knowledge of the responsibilities assigned to them according to NHM.

The present study also revealed that the mean \pm SD knowledge of study subjects was $7.31 \pm 1.35$ regarding concept of NHM, $9.91 \pm 1.22$ for maternal health services, $2.9 \pm 0.93$ for JSY services provided under NHM, $3.63 \pm$ 0.85 for JSSK services provided under NHM, $8.93 \pm 1.92$ for child health and immunisation, and $6.86 \pm 1.62$ for other miscellaneous services. Thus ASHA workers were having the highest knowledge regarding maternal health services, followed by child health and immunisation, concept of NHM, JSSK services provided under NHM, JSY services provided under NHM, and other miscellaneous services provided under NHM.

It is thus evident that there is a definite scope for improvement and enhancement in the various knowledge components of the study subjects. The study subjects need to update and abreast their knowledge regarding Janani Suraksha Yojana and other miscellaneous services for which their role is essentially sought. The general concepts and services for which they can play an active role in NHM are inevitable to be incorporated in their training. The study subjects need to update their information on Village Health Nutrition and Sanitation programme and have to work actively in all its components. This will help in bridging the gap between community health needs and contemporary health services through utilisation of local resources managed via an intersectoral approach in a more affordable and accessible manner at Primary Health Care level.

The present study revealed that $93.33 \%$ of study subjects obtained a practice score in the range of 11-15, followed by $5 \%$ in the range of $6-10$, and only $1.67 \%$ in the range of $1-5$. This study also concluded that the mean \pm SD of practice score was $12.58 \pm 1.6$. On further categorising the practice scores as poor, moderately adequate, and adequate, the study revealed that $93.33 \%$ of study subjects had adequate practice, $5 \%$ had moderately adequate practice, and only $1.67 \%$ had poor practice.

The findings of the present study are supported by a study conducted by Garg PK, Bhardwaj A, Singh A, Ahluwalia SK $(2013)^{9}$ on "An evaluation of ASHA worker's Awareness and 
Practice of their responsibilities in rural Haryana" on 105 ASHA workers. It was found in this study that ASHA workers (60\%-70\%) had adequate practice regarding antenatal care, postnatal care, immunisation, child health, maternal and reproductive health, family planning, birth and death registration, and sanitation services.

The findings of the present study are concurrent with the findings of another study conducted by Gupta A (2017), ${ }^{8}$ on "A Study on Knowledge and Practice of ASHA under NHM Programme of Allahabad District conducted on 405 ASHA workers" in Uttar Pradesh, India. It was found in this study that most of the ASHA workers (63.70\%) have adequate knowledge and practice in the field regarding NHM, and acquire more knowledge and practice effectively by working more and more in the field.

The study findings are similar to that of Meena R, Raj $D$, Saini L, Tomar A, Khanna M, Gaur K (2016), ${ }^{10}$ conducted on "Knowledge status of Accredited Social Health Activist of Jaipur city on 172 ASHA workers". The study revealed that majority of ASHAs practice adequately and know their role in immunisation, antenatal care, and informing SubCentre/ PHC/ CHC about births and deaths in the village. The majority (> 80\%) of ASHAs knew their role in postnatal check-up (PNC), counselling women for birth preparedness, safe delivery, exclusive breastfeeding, complementary feeding, and personal hygiene and sanitation.

The present study has also revealed that $95 \%$ of ASHA workers used to register pregnant women in the period of 12-16 weeks of gestation, 93\% used to counsel pregnant women for ANC, $87 \%$ used to guide them for PNC, and $93 \%$ reported that they accompany and escort pregnant women to the hospital. $98 \%$ of the ASHA workers have a practice of distributing oral pills, ORS, and iron and folic acid tablets to beneficiaries. It was found during this study that only $52 \%$ of ASHAs practice as DOTS provider. Moreover, $90 \%$ of ASHA workers have a practice of informing AWW and ANM on new births and deaths in their local community. 97\% of ASHA workers work in coordination with AWW in supplementary feeding of under-five children and expecting women. 95\% of ASHA workers reported that they assist ANM in immunisation of children against 7 killer diseases. 95\% of ASHA workers motivate eligible couples (having more than two children) for family planning. Maximum (90\%) ASHA workers help AWW in supplementary feeding programme. $92 \%$ of the ASHA workers have a practice of inviting all beneficiaries a day before VHN\&S committee meeting to discuss the health issues. $83 \%$ of ASHA workers are active in spreading awareness and education by participating in the related programmes regarding TB/ AIDS in the community and work along with other health officials. 92\% of ASHA workers help the community to get latrines constructed and motivate them to do so by all possible means through total sanitation campaign and Swachh Bharat Abhiyan.

The study findings of the present study are also supported by Gupta A (2017), ${ }^{8}$ in a study conducted on "A Study on Knowledge and Practice of ASHA under NHM Programme of Allahabad District on 405 ASHA workers" in Uttar Pradesh, India. The study revealed that all the respondents included registration of pregnant mother, counselling on ANC and PNC, safe delivery, immunisation, and accompanying pregnant mother to the hospital as part of their routine duties. Distribution of ORS, IFA, and oral pills are not the regular activities as reported. Only 35\% of ASHA workers reported for the distribution of DOTS. 84.44\% informed AWW/ ANM on birth and death. 90.62\% helped AWW in supplementary nutrition feeding.

The findings of the present study are also concurrent with Shashank KJ, Angadi MM (2015), ${ }^{11}$ who conducted "A study to evaluate the knowledge of ASHA workers on antenatal and postnatal care in Bijapur district on 132 ASHA workers" India. The study showed that $90.9 \%$ were aware of and distributed IFA and calcium tablets for the antenatal mothers.

The findings of the present study are also supported by another study conducted by Swathi S, Sumit K, Sameer P $(2018)^{12}$ on, “A study on assessment of ASHA's work profile in context of Uduppi Taluk, Karnataka, India among 100 ASHA workers". The study revealed that $97 \%$ of the ASHA workers reported that they were informing the concerned about births and deaths in their respective villages. $77 \%$ of ASHA workers were also helping in creating awareness in the community to send their under-five child to Anganwadi centre.

The study findings revealed that there was a statistically significant association between the knowledge score of ASHA workers regarding services provided under NHM and educational status $(p=0.014)$, and no significant association was seen between knowledge and other demographic variables (age, marital status, experience, and in-service training received under $\mathrm{NHM}$ ).

The findings of the present study are supported by Bhanderi JD, Arunkumar RV, Sharma DB (2018) $)^{13}$ in their study on "Evaluation of accredited social health activists in Anand Gujarat". The study revealed that there is no association of knowledge and performance scores of ASHA workers with age $(p=0.905)$, educational status $(p=0.113)$, and service period $(p=0.549)$.

The study findings revealed that there was statistically no significant association between the practice score of ASHA workers regarding services provided under NHM and demographic variables [age $(p=0.20)$, educational status 
$(p=0.60)$, marital status $(p=0.10)$, experience $(p=0.40)$, and in-service training received under $\operatorname{NHM}(p=0.90)]$.

The findings of the present study are supported by a study conducted by Sindhu JV (2019) $)^{14}$ on "Knowledge and reported Practice of ASHA workers regarding infant care in selected PHCs under Anekal Taluk, Bangalore". It was revealed in their research study that there was no association of practice with age $(p=0.32)$, education $(p=$ $0.42)$, marital status $(p=0.51)$, experience $(p=0.33)$, and in-service training programmes attended $(p=0.37)$.

The findings of the present study are contrary to the findings of Mohapatra A, Mohapatra SC (2013) 7 in their study entitled, "Intra-organizational human resource auditing of ASHA's in Harahua block of Varanasi". The study revealed that there is a significant association of performance of ASHA under NRHM with caste $(p=0.040)$, educational status $(p=0.001)$, and years of service $(p=0.041)$.

The present study revealed that the correlation between knowledge and practice of ASHA workers regarding services provided under NHM are positively (moderately strong correlation) ${ }^{15}$ related as $r$ calculated value is 0.69 , and $r$ tabulated value is 0.25 , with $p=0.001$, and $58(\mathrm{~N}-2)$ degree of freedom.

The study finding is statistically significant at 0.01 level. So there is a significant strong positive correlation between knowledge and practice of ASHA workers, as far as rule of thumb is concerned. ${ }^{16}$

The findings of the present study are also supported by a study conducted by Sindhu JV (2019)14 on "Knowledge and reported Practice of ASHA workers regarding infant care in selected PHCs under Anekal Taluk, Bangalore", which was conducted on 79 ASHA workers. It was revealed in their research study that there is a significant positive correlation between knowledge and practice of ASHA workers $(r=$ $0.86, p=0.000$ ).

\section{Nursing Implications}

The study findings have several implications in nursing. They can be categorised under the following headings:

- Nursing Practice

- Nursing Education

- Nursing Research

- Nursing Administration

\section{Nursing Practice}

1. It is the responsibility of the Public Health Nurses, Community Health Nurses, and Community Health Officers to educate the ASHA workers regarding National Health Mission, and services provided through this mission to the general public and special sections of the society. This information should be disseminated among lower rung nursing professionals like ANM and FMPHW who work as ASHA facilitators and ASHA coordinators at block and district levels.

2. Nursing professionals themselves need to improve and update their knowledge regarding National Health Mission (NHM), maternal health services, JSY, JSSK, child health, immunisation, and miscellaneous services like family planning, sanitation, village health etc.

3. Teaching programmes can be conducted for ASHA workers, ANM cum ASHA facilitators, ASHA coordinators and nursing professionals as they would allow all of these community health workers to enhance their knowledge regarding NHM, programmes implemented through NHM, and services provided under NHM.

4. Community Health Nurses and Community Health Officers working at Health and Wellness Centres should use their knowledge to educate community health workers and the general public regarding major services provided under NHM to link the community with health care services very effectively.

\section{Nursing Education}

1. Nurse educators working in the Regional Institute of Health and Family Welfare (RIHFW) and Kashmir Skills and Simulation Centres (KSSC) located at Dhobiwan Tangmarg of Baramulla district should educate the ancillary nursing professionals like ANM and MMPHW regarding various programmes, benefits, and incentives provided under various schemes to the general or a particular section of the society.

2. Nurse educators meant for nursing practitioners of different cadres and other health care staff, appointed through NHM at State accredited vocational institute (No. 572101 affiliated with National Institute of Open Schooling) under RIHFW, Dhobiwan Tangmarg should impart and refine skills of health care workers. They should assess and evaluate these skills at the same time so that hurdles and difficulties in the field can be minimised.

3. More information should be provided to the community health nursing students regarding the NHM, NRHM, NUHM, RCH, maternal health, JSY, JSSK, newborn care, child health, immunisation, VHSNC, and other miscellaneous services. They can educate the community health workers while in the field or in clinical placement working along with these community health workers like ASHA, AWW, ANM, MPHW etc.

4. The nursing curriculum should be strengthened by equipping with knowledge regarding various teaching strategies to disseminate health information, advanced technology in the medical profession related to NHM, programme implementation under this scheme, and benefits for the community.

5. Students can be encouraged to take up projects and 
research studies related to ASHA workers, community health workers, community health officers, and medical officers to know how well the information regarding NHM is disseminated and how services are utilised. Moreover, evaluation studies regarding each component of NHM can be undertaken by nursing practitioners in Community Health.

\section{Nursing Administration}

1. Community Health Nurses as administrators should take initiation in formulating information booklets, structured teaching programmes, translation of material to languages understandable to ASHA workers, formulation of guidelines for working in community settings, online lectures, and discussions via WhatsApp groups.

2. Community Health Nurses should effectively collaborate with the administrators of sub-district hospitals, primary health centres, and simulation labs with an objective to enhance the knowledge of ASHA workers and motivate them to embrace technology and changes in society. This will again help in bridging the gap between community and healthcare services.

3. Community Health Nurses along with administrators from a medical background like Block Medical Officers, Medical Officers etc. should organise the inservice educational programmes, modular training, and refresher courses for ASHA workers and other community health workers to enhance their knowledge and motivate them to participate in such activities, by providing incentives, reinforcement, and certificates of appreciation.

\section{Nursing Research}

1. The findings of the present study suggest that the administration should encourage ASHA workers to read, discuss, and participate in research activities in order to improve their knowledge regarding National Health Mission and services provided under the ambit of NHM.

2. The study also suggests that encouragement should be provided to disseminate knowledge by publications, lectures, information booklets, ASHA modules, and organising training, workshops, conferences, and seminars at appropriate locations for the welfare of all.

\section{Limitations}

1. Generalisation is not possible since the sample is limited (60), and setting is Primary Health Centres of Tangmarg, only one block of Baramulla.

2. The researcher used non-experimental descriptive (correlative) research design. Hence the researcher had observed and described what has come to the fore. The same was correlated with previously done studies in order to know the studies that are in support of findings and their revelations, and those that are contrary to the results of the study.

3. A one-time assessment was done and the study was related to a few components of the National Health Mission.

4. The practice assessed was expressed practice and self-reported practice, as it was not possible for the researcher to observe the same under prevailing conditions of COVID-19 pandemic.

\section{Recommendations}

1. This study can be replicated in a different setting with a larger group.

2. A comparative study can be done using Primary Health Centres of various blocks, various districts, or urban and rural settings.

3. A similar study can be done on different community health workers like ANM, MPHW's, staff nurses, public health nurses, and community health officers.

4. A similar study can be recommended to evaluate the effectiveness of a structured teaching programme or a video-assisted programme on knowledge and practice of ASHA workers regarding services provided under the National Health Mission.

5. A similar study can be recommended to compare the knowledge and practice of ASHA workers regarding services provided under the National Health Mission in selected urban and rural health centres of Srinagar, Kashmir.

6. A structured teaching practice can be developed based on the existing learning needs of ASHA workers.

7. Evaluation studies can be conducted on different services and programmes of NHM with a varying population ranging from beneficiaries to health care workers.

\section{Source of Funding: Self \\ Conflict of Interest: None}

\section{References}

1. Park K. Text Book of Preventive and Social Medicine. 19th ed. Jabalpur: M/S Banarasidas Bhanot; 2007. 364p.

2. Ray SK. National Rural Health Mission-Opportunity for Indian Public Health Association. Indian J Pub Health 2005; 49(3): 171-4.

3. The Government of India. National Rural Health Mission (2005-12), Mission Document.

4. National Health Mission. Update on ASHA programme January 2017.

5. Peer M. Three thousand ASHAs appear in NIOS exam. 2020 Jan 29.

6. Excelsior Correspondent [Internet]. ASHA programme of J\&K under NHM awarded at National level. Daily 
Excelsior. 2016 Sep 3. Available from: https://www. dailyexcelsior.com/asha-programme-jk-nhm-awardednational-level/

7. Mohapatra A, Mohapatra SC. Intra-organizational human resource auditing of ASHAs in Harahua block of Varanasi. J Public Health Epidemiol 2013; 5(2): 37-42.

8. Gupta A, Gupta N. A Study on Knowledge and Practice of ASHA under NHM Programme of Allahabad District. Shalom Institute of Health and Allied Sciences Sam Higginbottom University of Agriculture, Technology \& Sciences, Krishikosh Institutional Repository.

9. Garg PK, Bhardwaj A, Singh A et al. An Evaluation of ASHA Worker's Awareness and Practice of their Responsibilities in Rural Haryana. Natl J Community Med 2013; 4(1): 76-80.

10. Meena R, Raj D, Saini L et al. Knowledge status of Accredited Social Health Activist (ASHA) of Jaipur city. Intern Multispeciality J Health 2016; 2(12): 18-25.

11. Shashank KJ, Angadi MM. A study to evaluate the knowledge of ASHA workers on antenatal and postnatal care in Bijapur district. Intern J Res Med Sci 2015; 3(9): 2299-302.

12. Shet S, Kumar S, Sameer P. A study on assessment of ASHA's work profile in context of Uduppi Taluk, Karnataka, India. Clin Epidem Global Health 2018; 6(3): 143-7. DOI: http://doi.org/10.1016/j.cegh. 2017.08.004

13. Bhanderi DJ, Varun AR, Sharma DB. Evaluation of accredited social health activist in Anand District of Gujarat. J Family Med Prim Care 2018; 7(3): 571-576.

14. Sindhu JV. Knowledge and reported Practice of ASHA workers regarding infant care in selected PHCs under Anekal Taluk, Bangalore. Intern J Nurs Sci Prac Res 2019; 5(1): 24-8.

15. Shrivastava SR, Shrivastava PS. Evaluation of trained accredited social health activist (ASHA) workers regarding their knowledge, attitude and practices about child health. Rural Remote Health 2012; 12(4): 2099.

16. Krehbiel TC. Correlation coefficient Rule of thumb. Deci Sci J Innov Edu 2004; 2(1): 97-100. 


\section{Appendix}

\section{Tools of Data Collection}

\section{Section I}

\section{Demographic Variables}

1. Age in years

2. Educational Status

2.18 th

$2.3 \quad 10$ th

$2.3 \quad 12$ th

2.4 Graduate

2.5 Any other

3. Marital Status

3.1 Married

3.1 Unmarried

3.1 Other

4. Years of Experience

$4.1 \quad 01-05$

$4.2 \quad 06-10$

$4.3 \quad 11-15$

$4.4 \quad 16-20$

5. In-service training received under NHM

5.1 Yes

5.2 No

\section{Section II: Knowledge Assessment of Asha Workers regarding Services Provided Under National Health} Mission

\section{Part A: Concept of National Health Mission}

1. The aims of National Health Mission include

1.1 Primary health care and mainstreaming ISM

1.2 Integration of health concerns with health determinants

1.3 Decentralisation of services

1.4 All of the above

2. NRHM was initially launched for a period of

2.106 years

2.207 years

2.308 years

$2.4 \quad 09$ years

3. NHM includes sub-missions EXCEPT

3.1 National Rural Health Mission

3.2 National Urban Health Mission

3.3 National Sub Rural and Sub Urban Health Mission

3.4 National Rural and Urban Health Mission

4. NRHM was launched on/ by

4.1 April 12 2002/ President of India

4.2 April 12 2003/ Chief Justice of India 
4.3 April 12 2004/ Ministry of Health \& Family Welfare

4.4 April 12 2005/ Prime Minister of India

5. The goals of NHM are all EXCEPT

5.1 Increase Couple Protection Rate

5.2 Reduce MMR to $1 / 1000$ live births

5.3 Reduce IMR to 25/1000 live births

5.4 Reduce TFR to 2.1

6. NHM was established in

6.1 April 2013

6.2 May 2013

$6.3 \quad$ November 2013

6.4 December 2013

7. The ratio of Centre state funding in rupees for J\&K under NHM is

$7.170: 25$

$7.260: 40$

$7.390: 10$

$7.450: 50$

8. The services provided under NHM include following EXCEPT

8.1 Maternal and Reproductive Health Services

8.2 Child Health and Immunisation Services

8.3 Village Health, Nutrition, and Sanitation Services

8.4 Surgical treatment for various ailments

9. NRHM was initially launched in states/ UTs of India

$9.118 / 0$

$9.225 / 0$

$9.328 / 0$

9.4 All of the states and UTs

10. NUHM covers all state capitals/ district HQ/ towns with a population of or above

$10.130,000$

$10.250,000$

$10.370,000$

10.41 lakh

\section{Part B: Maternal Health Services provided under NHM}

11. Maternal health services focus on all EXCEPT

11.1 Menstrual health, hygiene, fertility and pregnancy care

11.2 Medical termination pregnancy services

11.3 Incentives for institutional deliveries

11.4 Antenatal, intranatal and postnatal services

12. Pregnant women should be registered between....... weeks of pregnancy

$12.1 \quad 04-06$

$12.2 \quad 06-08$

$12.3 \quad 08-10$

$12.4 \quad 12-16$ 
13. The danger signs of pregnancy include all EXCEPT

13.1 Chloasma (face mask) and abdominal striations (Striae Gravidum)

13.2 Vaginal bleeding \& convulsions

13.3 Severe headache \& abdominal pain

13.4 Swelling of legs \& hands

14. The minimum antenatal visits for a pregnant woman are

14.103

14.204

14.305

14.406

15. The vaccine that must be given to pregnant women is

15.1 OPV

15.2 Measles

15.3 Tetanus Toxoid

15.4 Diptheria

16. During pregnancy the energy (calorie) requirement is

16.1 Same as in other days

16.2 Less than normal intake

16.3 Depending on physical constitution

16.4 More than normal intake

17. A pregnant woman consumes iron and folic acid tablets daily for

17.1 At least 3 months during antenatal period

17.2 At least 9 months during antenatal period

17.3 At least 3 months during postnatal period

17.4 At least 9 months during postnatal period

18. During postnatal period, undernourished woman is provided nutritional supplements by

18.1 Sub Centre and PHC

18.2 Anganwadi Centre by AWW

18.3 Women welfare society

18.4 All of the above

19. Following assessment is done during pregnancy checkup and care, most of the time EXCEPT

19.1 History taking, measuring of height and weight

19.2 Checking blood pressure, Breast self-examination

19.3 Per vaginal examination

19.4 Abdominal palpation and other baseline investigations

20. All pregnant women should have

20.1 Early antenatal registration

20.2 Minimum 4 antenatal visits

20.3 Institutional delivery as far as possible

20.4 All of the above

\section{Part C: JSY services provided under NHM}

21. JSY stands for

21.1 Janani Suraksha Yojana

21.2 Janani saiva Yojana

21.3 Janani Shishu Yojana

21.4 Jeevan Shishu Yojana 
22. JSY \& RCH is implemented to

22.1 Help all women

22.2 Reduce maternal and infant mortality

22.3 Promote institutional deliveries

22.4 Both $22.2 \& 22.3$

23. The cash assistance for institutional delivery of urban pregnant women in J\&K is Rupees

23.1700

23.21400

23.31000

23.42500

24. The cash assistance for home delivery of BPL pregnant women is Rupees

$24.1 \quad 100$

24.2300

24.3500

24.4700

25. The contribution of Centre government in terms of financial support towards JSY is

$25.1100 \%$

$25.290 \%$

$25.380 \%$

$25.470 \%$

\section{Part D: JSSK services provided under NHM}

26. JSSK stands for

26.1 Janani Suraksha Shishu Karyakaram

26.2 Janani Shishu Suraksha Karyakaram

26.3 Janani Sundarya Sevakendra

26.4 Jeewan Shishu Sukarsha Karyakaram

27. JSSK was launched on

27.1 1st June 2009

27.2 1st June 2010

27.3 1st June 2011

27.4 1st June 2012

28. The free entitlements for pregnant women under JSSK are all EXCEPT

28.1 Cashless delivery and drugs

28.2 Free diagnostics, diet, and transport

28.3 Free caesarean section and referral services

28.4 Free clothing, blankets for home care

29. The free entitlements for sick newborn under JSSK are all EXCEPT

29.1 Weaning foods

29.2 Free diagnostics, provision for blood

29.3 Free transport and referral facilities

29.4 Free treatment, drugs, consumables

30. Free treatment benefits and zero expense delivery is provided to all EXCEPT

30.1 Pregnant women

30.2 Geriatrics

30.3 Infant

30.4 Newborn 


\section{Part E: Child health and immunisation services provided under NHM}

31. The vaccine administered to a newborn at birth is

\subsection{Measles}

31.2 T.T.

31.3 BCG

31.4 All of these

32. BCG provides immunity against

32.1 Hepatitis

32.2 Whooping cough

32.3 Poliomyelitis

32.4 Tuberculosis

33. The age at which Measles vaccine is administered is

33.19 months

33.26 months

33.33 months

33.412 months

34. 34 DPT vaccine is used in all EXCEPT

34.1 Diphtheria

34.2 Typhoid

34.3 Tetanus

34.4 Pertussis

35. The full form of OPV is

35.1 Oral Pneumococcal Vaccine

35.2 Oral Pertussis Vaccine

35.3 Oral Polio Vaccine

35.4 Oral Protective Vaccine

36. Zero dose of OPV is given at the age of

36.1 At birth

36.206 weeks

36.310 weeks

36.414 Weeks

37. The first dose of vitamin $A$ is given at the age of

37.109 months

37.215 months

37.318 months

37.424 months

38. Rotavirus vaccine is administered for

38.1 Severe cough

38.2 Severe diarrhoea

38.3 Severe weakness

38.4 Severe malnutrition

39. ORS helps in the treatment of

39.1 Eye infections

39.2 Cough

39.3 Diarrhoea

39.4 All of the above 
40. Exclusive breastfeeding in baby is recommended for a period of

40.103 months

40.204 months

40.305 months

40.406 months

\section{Part F: Other miscellaneous services (Village Health, Nutrition, Sanitation) provided under NHM}

41. Diseases transmitted by mosquito are all EXCEPT

41.1 Hepatitis

41.2 Dengue fever

41.3 Malaria \& yellow fever

41.4 Chikungunya

42. The breeding places for mosquitoes are all EXCEPT

42.1 Stagnant water

42.2 Covered water tanks and reservoirs

42.3 Other artificial containers holding water

42.4 Tin cans, discarded tires

43. Kerosene spray is used in stagnant waters for the prevention of

43.1 Breeding of viruses

43.2 Breeding of bacteria

43.3 Breeding of mosquito

43.4 Breeding of parasites

44. The drugs that are available in ASHA kit are

44.1 Paracetamol \& ORS packets

44.2 Dicyclomine hydrochloride

44.3 Contraceptive pills \& Povidine ointment

44.4 Iron folic acid \& zinc yablets

45. ASHA equipment kit contains

45.1 Baby blanket

45.2 Thermometer \& weighing scale

45.3 Digital wrist watch

45.4 All of the above

46. Village Health Sanitation \& Nutrition Committee comprises all EXCEPT

46.1 Panchayat members, health workers

46.2 BMO, CMO and MLA

46.3 Minimum 15 members of the community

46.4 ASHA, vulnerable sections and community members

47. ASHA in Village Health Sanitation \& Nutrition committee acts as

47.1 Chairman

47.2 President

47.3 Member secretary and Convener

47.4 Cashier

48. Behaviour change communication, counselling, linkage with Anganwadi worker, Ancillary nurse midwife and multi-purpose worker is the task of

48.1 Public health nurse

48.2 Village health guide

48.3 Lady health visitor

48.4 ASHA 
49. 49 ASHA has to maintain registers for

49.1 Births, stillbirths and deaths

49.2 Her own work as ASHA diary

49.3 Both 49.1 and 49.2

49.4 None of these

50. Family planning services provided under NHM are

50.1 Use of condoms and diaphragm

50.2 Tubectomy

50.3 Vasectomy

50.4 All of the above

\section{Section III: Checklist for Assessing Practice regarding Services Provided Under National Health Mission}

Do you perform the following activities/ practices?

1. Registers pregnant women

Yes

No

2. Counsels pregnant women for antenatal care

Yes

No

3. Counsels pregnant women for postnatal care

Yes

No

4. Counsels women for safe delivery

Yes

No

5. Accompanies pregnant women to hospital

Yes

No

6. Distributes iron and folic acid, oral pills, ORS

Yes

No

7. Distributes DOTS among active TB patients

Yes

No

8. Inform Anganwadi worker/ ANM on new births and deaths in the community

Yes

No

9. Helps Anganwadi worker in supplementary feeding of under-five children and expecting women

Yes

No

10. Helps Ancillary nurse midwife in immunisation of children

Yes

No 
11. Motivates the couple for family planning

Yes

No

12. Participates in Supplementary Nutrition Programmes

Yes

No

13. Invites all beneficiaries a day before Village Health Sanitation \& Nutrition Committee meeting Yes

No

14. Participates in creating awareness regarding TB and HIV/ AIDS

Yes

No

15. Motivates households for construction of latrines

Yes

No 